\title{
Comparing microbial and chemical kinetics for modelling soil organic carbon decomposition using the DecoChem v1.0 and DecoBio v1.0 models
}

\author{
G. Xenakis ${ }^{1, *}$ and M. Williams ${ }^{1}$ \\ ${ }^{1}$ School of GeoSciences, University of Edinburgh, Crew Building, The King's Buildings, West Mains Road, Edinburgh, \\ Midlothian, EH9 3JN, UK \\ *now at: Forest Research, Northern Research Station, Roslin, Midlothian, EH25 9SY, UK
}

Correspondence to: M. Williams (mat.williams@ed.ac.uk)

Received: 30 October 2013 - Published in Geosci. Model Dev. Discuss.: 7 January 2014

Revised: 16 May 2014 - Accepted: 16 June 2014 - Published: 24 July 2014

\begin{abstract}
Soil organic matter is a vast store of carbon, with a critical role in the global carbon cycle. Despite its importance, the dynamics of soil organic carbon decomposition, under the impact of climate change or changing litter inputs, are poorly understood. Current biogeochemical models usually lack microbial processes and thus miss an important feedback when considering the fate of carbon. Here we use a series of modelling experiments to evaluate two different model structures: one with a standard first-order kinetic representation of soil decomposition (DecoChem v1.0, hereafter chemical model) and one with control of soil decomposition through microbial activity (DecoBio v1.0, hereafter biological model). The biological model includes cycling of organic matter into and out of microbial biomass, and simulates the decay rate as a functional of microbial activity. We tested two hypotheses. First, we hypothesized different responses in the two models to increased litter inputs and glucose additions. In the microbial model we hypothesized that this perturbation would prime microbial activity and reduce soil carbon stocks; in the chemical model we expected this perturbation to increase $\mathrm{C}$ stocks. In the biological model, responses to changed litter quantity were more rapid, but with the residence time of soil $\mathrm{C}$ altering such that soil $\mathrm{C}$ stocks were buffered. However, in the biological model there was a strong response to increased glucose additions (i.e. changes in litter quality), with significant losses to soil C stocks over time, driven by priming. Secondly, we hypothesized that warming will stimulate decomposition in the chemical model and loss of $\mathrm{C}$, but in the biological model soil $\mathrm{C}$ will be less sensitive to warming, due to complex microbial feedbacks. The
\end{abstract}

numerical experiments supported this hypothesis, with the chemical model soil $\mathrm{C}$ residence times and steady-state $\mathrm{C}$ stocks adjusting strongly with temperature changes, extending over decades. On the other hand, the biological model showed a rapid response to temperature that subsided after a few years, with total soil $\mathrm{C}$ stocks largely unchanged. The microbial model shows qualitative agreement with experimental warming studies that found transient increases in soil respiration that decline within a few years. In conclusion, the biological model is largely buffered against bulk changes in litter inputs and climate, unlike the chemical model, while the biological model displays a strong priming response to additions of labile litter. Our results have therefore highlighted significantly different sensitivities between chemical and biological modelling approaches for soil decomposition.

\section{Introduction}

Soils are a major carbon store, of which approximately $50 \%$ can be found in the northern circumpolar permafrost region (NCPR), an area covering only $16 \%$ of the total global area (Tarnocai et al., 2009). Recent estimates found that total soil organic carbon (SOC) of the NCPR is approximately $1672 \mathrm{PgC}$ with $88 \%$ of the carbon locked in perennially frozen soils and deposits. The majority of these are deep soils with $1024 \mathrm{Pg} \mathrm{C}$ in the first $3 \mathrm{~m}$ (Tarnocai et al., 2009). In the Arctic region in particular, stocks in permafrost soil are significantly higher (1400-1850 Pg C) than vegetation stocks 
(60-70 Pg C) (Tarnocai et al., 2009). Soils are likely a sink of atmospheric $\mathrm{CO}_{2}$ at a rate of approximately $0.4 \mathrm{Pg} \mathrm{C}_{\text {year }}{ }^{-1}$ ( $25 \%$ of the total ocean-land exchange), although this is uncertain (McGuire et al., 2009). Thus soils play an important role in the context of the global carbon cycles (McGuire et al., 2009).

Despite such importance, the sensitivity to climate change of SOC over different timescales, from hours to decades, is unknown (McGuire et al., 2009; Schmidt et al., 2011; Sanderson et al., 2011). Current state-of-the-art biogeochemical models have tended to represent SOC decomposition as a first-order kinetic process, using various linked soil $\mathrm{C}$ pools of differing lability, with an exponential sensitivity to temperature and a non-linear response to soil moisture (Fenner and Freeman, 2011; Ise et al., 2008; Jorgenson et al., 2010; Koven et al., 2011; Rogers et al., 2011; Wisser et al., 2011), for instance the DeNitrofication and DeComposition model (DNDC) ( $\mathrm{Li}$ et al., 1992, 1997), the grass and agroecosystems dynamic model (CENTURY) (Parton et al., 1988; Metherell et al., 1993), the Rothamsted Carbon model (RothC) (Jenkinson and Rayner, 1977; Coleman et al., 1997) and the Estimating Carbon in Organic Soils - Sequestration and Emissions model (ECOSSE) (Smith et al., 2007, 2010). However, there are still a number of issues that are not presently addressed by these models, for instance the priming of recalcitrant soil C; these issues arise from recent field experiments and observations (Hartley et al., 2012) and limit the ability of these models to quantify the short- and longterm responses of soils to climate change.

Schmidt et al. (2011) characterize a number of challenges for improving models of SOC dynamics. One of these is to replace the SOC pools of varying lability with a cycling of organic matter into and out of microbial biomass. Another recommendation is to model the decay rate as a function of microbial activity. The focus of this paper is to compare a model based on these two recommendations (referred to here as the microbial or biological model) with the standard chemical model (as defined earlier), exploring steady-state properties, and their sensitivity to litter inputs of different quality and amount, and their temperature sensitivity.

In so doing we test two hypotheses:

H1 Increased litter inputs and glucose addition will prime microbial activity and reduce SOC stocks in the biological model, but will increase SOC stocks in the chemical model.

H2 Warming will stimulate decomposition in the chemical model and loss of SOC, but in the biological model the SOC will be less sensitive to warming, due to complex interactions between SOC and the microbial pool.

The evaluation here is focused on model comparison, but is undertaken in an Arctic context, using meteorological data and carbon stock measurements, for forcing and initial conditions, from a research site in northern Sweden (Sloan et al.,
2013). Using biological and chemical SOC models applied in an Arctic context, our science objective is first to demonstrate steady-state behaviour consistent with observed SOC and litter inputs. Then for each model we evaluate how much SOC will change by altering litter inputs (including changing litter quality) and how SOC is affected by temperature changes. This novel analysis provides critical information on model sensitivity vital for interpretation of any new regional or global simulations using models with microbial components for SOC decomposition.

\section{Material and methods}

To test our hypotheses and address the science objective, we developed and evaluated two simple models representing two different concepts of SOC decomposition: DecoChem v1.0 (hereafter chemical model) and DecoBio v1.0 (hereafter biological model). The models have an hourly time step, and so resolve diel cycles. However, there is no spatial detail, i.e. no representation of variations through the soil profile. In both cases litter inputs to the model were fixed and constant, for simplicity. The chemical model was based on the concept that decomposition is dependent on the chemistry of the soil organic matter and temperature (Li et al., 1992, 1997; Liski et al., 2005; Metherell et al., 1993; Parton et al., 1988; Smith et al., 2007, 2010). The biological model was based on the concept that decomposition is dependent on microbial biomass and activity (Panikov, 1995; Blagodatsky et al., 1998, 2010) and addresses the two challenges of Schmidt et al. (2011) outlined above. In the terminology of Wutzler and Reichstein (2008), the chemical model involves nonexplicit representation of decomposer biomass in SOC decomposition, with the assumption that each pool of SOC has its own decomposer community in consistent equilibrium. On the other hand, the biological model includes a non-linear representation of a single decomposer community that determines decomposition of all SOC pools, with its microbial biomass and activity out of equilibrium with the substrate pools. The first stage of decomposition from fresh litter to SOC is simulated similarly in both models. It is the second stage of decomposition, the turnover of SOC, that is simulated differently and compared here. For both models moisture effects on processes were not included for simplicity.

\subsection{Modelling litter decomposition}

In both model versions decomposition processes occur in two stages. In the first stage, litter from foliage, roots and wood is deposited to their respective litter pools, represented by three state variables (Fig. 1). Each litter pool decomposes using a specific turnover rate $\left(k_{i}, \mathrm{~h}^{-1}\right.$, Table 1 , where $i=$ fol, root and wood for foliage, root and wood) which is limited by a temperature response function (Eq. 1) based on a $Q_{10}$ value of 1.4 (Mahecha et al., 2010). 
Table 1. State variables, parameters and fluxes of both the biological and chemical model.

\begin{tabular}{|c|c|c|c|c|c|}
\hline \multirow[b]{2}{*}{ Symbols } & \multirow[b]{2}{*}{ Description } & \multirow[b]{2}{*}{ Units } & \multicolumn{2}{|c|}{ Value } & \multirow[b]{2}{*}{ Reference } \\
\hline & & & Chemical & Biological & \\
\hline \multicolumn{6}{|l|}{ Parameters } \\
\hline$k_{\text {fol }}$ & Decomposition rate for foliage litter pool & $\mathrm{h}^{-1}$ & 0.0001142 & 0.0001142 & Calibrated \\
\hline$k_{\text {root }}$ & Decomposition rate for root litter pool & $h^{-1}$ & 0.0000571 & 0.0000571 & Calibrated \\
\hline$k_{\text {wood }}$ & Decomposition rate for wood litter pool & $\mathrm{h}^{-1}$ & 0.0000228 & 0.0000228 & Calibrated \\
\hline$k_{\text {slow }}$ & Decomposition rate for slow soil pool & $h^{-1}$ & 0.0000011 & 0.0189945 & Schädel et al. (2013); Calibrated \\
\hline$k_{\text {fast }}$ & Decomposition rate for fast soil pool & $\mathrm{h}^{-1}$ & 0.0000114 & - & Calibrated \\
\hline$k_{\mathrm{mu}}$ & Second-order rate constant for microbial $\mathrm{C}$ uptake & $\mathrm{m}^{2} \mathrm{~g} \mathrm{C}^{-1} \mathrm{~h}^{-1}$ & - & 0.0047044 & Blagodatsky et al. (2010) \\
\hline$f_{\text {lignin }}$ & Fraction of lignin & - & 0.376 & 0.376 & Calibrated \\
\hline$e_{\mathrm{d}_{1}}$ & Efficiency of decomposition of the first-stage decomposition & - & 0.5 & 0.5 & Calibrated \\
\hline$e_{\mathrm{d}_{2}}$ & Efficiency of decomposition of microbial decomposition & - & - & 0.02 & Blagodatsky et al. (2010) \\
\hline$e_{\mathrm{u}}$ & Efficiency of substrate uptake by microbes & - & - & 0.62 & Blagodatsky et al. (2010); Calibrated \\
\hline$m_{\mathrm{d}_{x}}$ & Maximum microbial death rate & $h^{-1}$ & 0.01 & 0.01 & Blagodatsky et al. (2011); Calibrated \\
\hline$m_{\mathrm{d}_{i}}$ & Inhibition constant for microbial death rate & - & 0.213 & 0.213 & Blagodatsky et al. (2011) \\
\hline$m_{\mathrm{c}}$ & Maintenance coefficient & $\mathrm{h}^{-1}$ & - & 0.0208 & Blagodatsky et al. (2010) \\
\hline$i_{c}$ & Inhibition constant for $\mathrm{C}$-dependent microbial activity & $\mathrm{gCm}^{-2}$ & - & 154.09 & Blagodatsky et al. (2010) \\
\hline$Q_{10}$ & $Q_{10}$ temperature response & - & 1.4 & 1.4 & Mahecha et al. (2010) \\
\hline \multicolumn{6}{|c|}{ State variables } \\
\hline$C_{L_{\mathrm{f}}}$ & Foliage litter pool & $\mathrm{gC} \mathrm{m}^{-2}$ & 14.06 & 14.06 & Sloan et al. (2013) \\
\hline$C_{L_{\mathrm{r}}}$ & Root litter pool & $\mathrm{gC} \mathrm{m}^{-2}$ & 180.04 & 180.04 & Sloan et al. (2013) \\
\hline$C_{L_{\mathrm{W}}}^{L_{\mathrm{r}}}$ & Wood litter pool & $\mathrm{gC} \mathrm{m}^{-2}$ & 131.78 & 131.78 & Sloan et al. (2013) \\
\hline$C_{\text {slow }}$ & Slow soil carbon pool & $\mathrm{gC} \mathrm{m}^{-2}$ & 1243.21 & 3500 & Street et al. (2013); Blagodatsky et al. (2010) \\
\hline$C_{\text {fast }}$ & Fast soil carbon pool & $\mathrm{gCm}^{-2}$ & 0.58 & 0.58 & Blagodatsky et al. (2010) \\
\hline$C_{\mathrm{g}}$ & Soil carbon with added glucose & $\mathrm{gCm}^{-2} \mathrm{~h}^{-1}$ & & 0.000571 & - \\
\hline$C_{\text {microbes }}$ & Microbial biomass & $\mathrm{gC} \mathrm{m}^{-2}$ & - & 35.00 & Blagodatsky et al. (2010) \\
\hline$m_{\mathrm{d}}$ & Microbial death rate & $\mathrm{h}^{-1}$ & - & - & - \\
\hline$m_{\text {act }}$ & Microbial activity & - & - & - & - \\
\hline$m_{\text {act }_{i}}$ & Initial microbial activity & - & - & 0.0585 & Blagodatsky et al. (2010) \\
\hline$d_{\mathrm{m}_{\text {act }}}$ & Differential of microbial activity & $\mathrm{h}^{-1}$ & - & - & - \\
\hline \multicolumn{6}{|l|}{ Fluxes } \\
\hline$L_{\mathrm{f}}$ & Litterfall of foliage, root and wood & $\mathrm{h}^{-1}$ & 0.00642 & 0.00642 & Sloan et al. (2013) \\
\hline$L_{\mathrm{r}}$ & Litter carbon pool for foliage, root and wood & $\mathrm{h}^{-1}$ & 0.00287 & 0.00287 & Sloan et al. (2013) \\
\hline$L_{\mathrm{W}}$ & Litter carbon pool for wood & $\mathrm{h}^{-1}$ & 0.00391 & 0.00391 & Sloan et al. (2013) \\
\hline$R_{\mathrm{S}}$ & Total soil respiration & $\mathrm{gC} \mathrm{m}^{-2} \mathrm{~d}^{-1}$ & - & - & - \\
\hline$R_{\mathrm{d}}$ & Respiration from soil decomposition & $\mathrm{gCm}^{-2} \mathrm{~d}^{-1}$ & - & - & - \\
\hline$R_{1}$ & Respiration from litter decomposition & $\mathrm{gCm}^{-2} \mathrm{~d}^{-1}$ & - & - & - \\
\hline $\operatorname{sum} R_{\mathrm{S}}$ & Sum of total soil respiration over a year & $\mathrm{gC} \mathrm{m}^{-2}$ year $^{-1}$ & - & - & - \\
\hline $\operatorname{sum} L_{i}$ & Sum of of litter inputs over a year & $\mathrm{gC} \mathrm{m}^{-2}$ year $^{-1}$ & - & - & - \\
\hline
\end{tabular}

$t_{\mathrm{r}}=e^{\ln Q_{10} \cdot \frac{T}{10}}$

A constant hourly input of litterfall was set based on field measurements, different for each of the three structural pools $\left(L_{i}, \mathrm{~h}^{-1}\right.$, Table 1; Sloan et al., 2013). The change of each litter pool $\left(C_{L_{i}}, \mathrm{~g} \mathrm{C} \mathrm{m}^{-2}\right)$ per hourly time step is determined from litter input and output of the first stage of decomposition (Eq. 2), a simple first-order turnover.

$\frac{\mathrm{d} C_{L_{i}}}{\mathrm{~d} t}=L_{i}-t_{\mathrm{r}} \cdot k_{i} \cdot C_{L_{i}}$

where $i=$ fol, root and wood for foliage, root and wood respectively.

Part of the quantity decomposed during the first stage of decomposition moves to the next stage (either biological or chemical model) while the rest is emitted as respiration $\left(R_{1}\right.$, $\mathrm{g} \mathrm{C} \mathrm{m}^{-2} \mathrm{~d}^{-1}$; Eq. 3). How much of the decomposed carbon enters the second phase depends on the first-stage efficiency of decomposition $\left(e_{\mathrm{d}_{1}}\right.$, Table 1$)$ and temperature $\left(t_{\mathrm{r}}\right)$.

$R_{1}=\left(1-e_{\mathrm{d}_{1}}\right) \cdot t_{\mathrm{r}} \cdot k_{i} \cdot C_{L_{i}}$,

where $i=$ fol, root and wood for foliage, root and wood respectively. Differences in structure between the two models were introduced for the second stage of decomposition to illustrate the difference between the purely chemical decomposition versus that affected by microbial activity. Although the concept of splitting the total amount of carbon into two pools exists for both models, the major difference is in the structure of carbon flow (Fig. 1). 

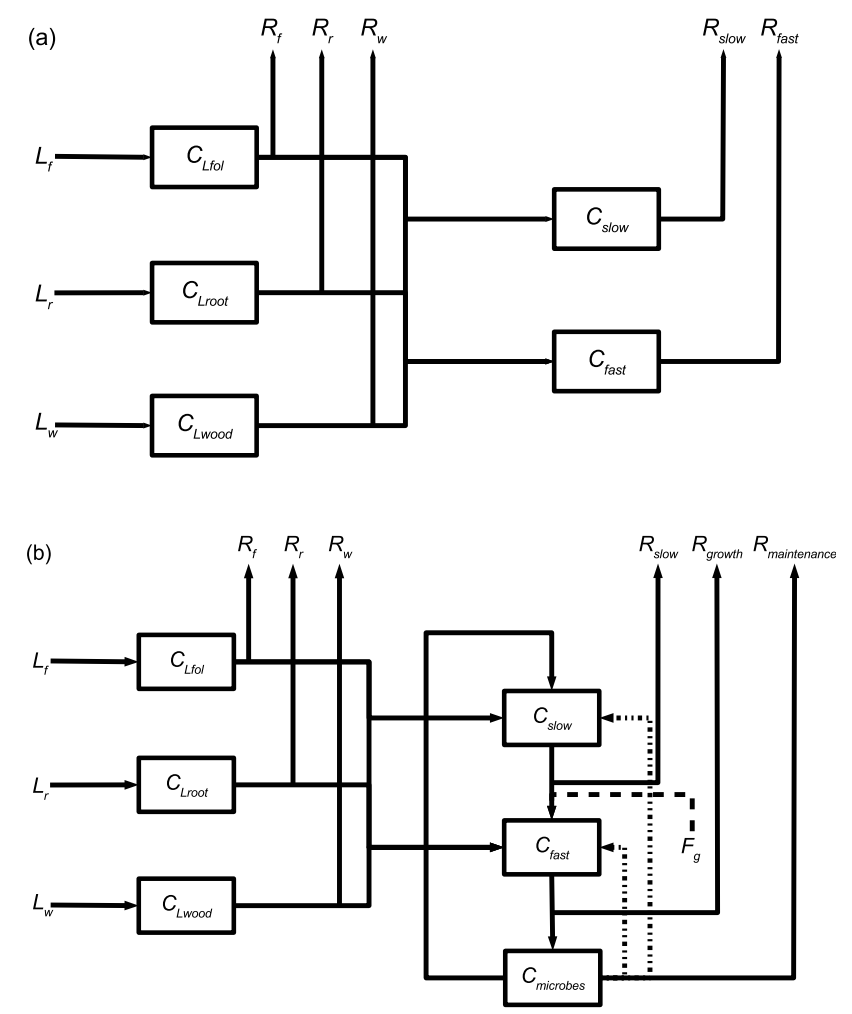

Figure 1. Model diagram for (a) the chemical and (b) the biological model. Boxes represent pools, arrows with solid lines fluxes and arrows with dotted lines influence of a variable on a process. $F_{\mathrm{g}}$ $\left(\mathrm{g} \mathrm{C} \mathrm{m}^{-2} \mathrm{~h}^{-1}\right)$ represents the input of glucose exudates for the litter quality experiment.

\subsubsection{DecoChem: a chemical model of SOC decomposition}

The chemical model has two state variables: a slow (recalcitrant) SOC pool $\left(C_{\text {slow }}, \mathrm{g} \mathrm{C} \mathrm{m}^{-2}\right)$ and a fast (labile) SOC pool $\left(C_{\text {fast }}, \mathrm{g} \mathrm{C} \mathrm{m}^{-2}\right)$. Carbon from $C_{\text {fast }}$ flows into $C_{\text {slow }}$ after decomposition (Fig. 1a) with a portion lost as respiration based on the efficiency of the first stage of decomposition $\left(e_{\mathrm{d}_{1}}\right)$. Decomposition of $C_{\text {fast }}$ (Eq. 4) is proportional to its size with a constant decomposition rate $\left(k_{\mathrm{fast}}, \mathrm{h}^{-1}\right)$ modified by temperature $\left(t_{\mathrm{r}}\right)$. Carbon inputs from the first stage of decomposition were kept similar to the biological model, with carbon being split into the two pools based on the litter fraction of lignin $\left(f_{\text {lignin }}\right.$, Table 1$)$ and with the lignin-based carbon compounds deposited into $C_{\text {slow }}$.

$\frac{\mathrm{d} C_{\mathrm{fast}}}{\mathrm{d} t}=\left(1-f_{\text {lignin }}\right) \cdot e_{\mathrm{d}_{1}} \cdot t_{\mathrm{r}} \cdot k_{i} \cdot C_{L_{i}}-t_{\mathrm{r}} \cdot k_{\mathrm{fast}} \cdot C_{\mathrm{fast}}$

$C_{\text {slow }}$ is further decomposed with a constant rate $\left(k_{\text {slow }}\right.$, $\mathrm{h}^{-1}$ ) and limited by $t_{\mathrm{r}}$, with the decomposed carbon removed from the pool as respiration (Eq. 5 and Fig. 1a).

$$
\begin{aligned}
\frac{\mathrm{d} C_{\text {slow }}}{\mathrm{d} t} & =f_{\text {lignin }} \cdot e_{\mathrm{d}_{1}} \cdot t_{\mathrm{r}} \cdot k_{i} \cdot C_{L_{i}}+e_{\mathrm{d}_{1}} \cdot t_{\mathrm{r}} \cdot k_{\text {fast }} \cdot C_{\text {fast }} \\
& -t_{\mathrm{r}} \cdot k_{\text {slow }} \cdot C_{\text {slow }}
\end{aligned}
$$

Respiration from soil decomposition is then calculated as the sum of respiration during decomposition of $C_{\text {fast }}$ and $C_{\text {slow }}$ (Eq. 6).

$R_{\mathrm{d}}=\left(1-e_{\mathrm{d}_{1}}\right) \cdot t_{\mathrm{r}} \cdot k_{\text {fast }} \cdot C_{\text {fast }}+t_{\mathrm{r}} \cdot k_{\text {slow }} \cdot C_{\text {slow }}$

Total soil heterotrophic respiration is calculated as the sum of respiration from litter and respiration from soil decomposition (Eq. 13).

\subsubsection{DecoBio: a biological model of SOC decomposition}

In the biological model, there are four state variables: a slow SOC pool, a fast SOC pool, a microbial pool $\left(C_{\text {microbes }}\right.$, $\mathrm{g} \mathrm{C} \mathrm{m}^{-2}$ ) and microbial activity $\left(m_{\text {act }}\right)$. We have adopted and adapted the concept of microbial activity as a dynamic variable, used to represent the impact of microbial biomass on decomposition processes (Blagodatsky et al., 1998, 2010). The activity depends on the size of the fast SOC pool (Eq. 7), which means microbes become more active when there is more labile carbon to consume. We also introduced a temperature limitation through $t_{\mathrm{r}}$, arguing that the microbial community becomes more active under warmer conditions. This parameter introduces an indirect effect of temperature for all soil processes associated with microbial activity.

$\frac{\mathrm{d} m_{\mathrm{act}}}{\mathrm{d} t}=t_{\mathrm{r}} \cdot k_{\mathrm{mu}} \cdot C_{\text {fast }} \cdot\left(\frac{C_{\mathrm{fast}}}{C_{\mathrm{fast}}+i_{c}}-m_{\mathrm{act}}\right)$

The dynamics of the activity is a modified MichaelisMenten response inhibited by the actual size of the parameter and in our study was allowed to vary between 0 and 1 .

Carbon from the first stage of decomposition is deposited to both $C_{\text {slow }}$ and $C_{\text {fast }}$ pools (Fig. 1b) based on $f_{\text {lignin }}$. Lignin-based carbon is allocated to $C_{\text {slow }}$ (Eq. 8) whereas the rest is allocated to $C_{\text {fast }}$ (Eq. 10).

$$
\begin{aligned}
\frac{\mathrm{d} C_{\text {slow }}}{\mathrm{d} t} & =f_{\text {lignin }} \cdot e_{\mathrm{d}} \cdot t_{\mathrm{r}} \cdot k_{i} \cdot C_{L_{i}}+t_{\mathrm{r}} \cdot m_{\mathrm{d}} \cdot C_{\text {microbes }} \\
& -k_{\text {slow }} \cdot m_{\text {act }} \cdot C_{\text {microbes }},
\end{aligned}
$$

where $i=$ fol, root and wood for foliage, root and wood respectively. Decomposition of $C_{\text {slow }}$ depends on the size of $C_{\text {microbes }}$, its microbial activity $m_{\text {act }}$ and a constant rate $\left(k_{\text {slow }}, \mathrm{h}^{-1}\right)$ of decomposition. A further input of carbon is deposited by microbial death, which is proportional to $C_{\text {microbes }}$ and a microbial death parameter $\left(m_{\mathrm{d}}, \mathrm{h}^{-1}\right.$, Eq. 8$)$. 
$m_{\mathrm{d}}$ is determined by a Michaelis-Menten function (Eq. 9) adapted by Blagodatsky et al. (2011) using a maximum rate $\left(m_{\mathrm{d}_{x}}, \mathrm{~h}^{-1}\right)$ and an inhibition constant $\left(m_{\mathrm{d}_{i}}\right)$

$m_{\mathrm{d}}=\frac{m_{\mathrm{d}_{x}}}{1+m_{\mathrm{d}_{i}} \cdot C_{\mathrm{fast}}}$.

A portion of the carbon flowing out of the $C_{\text {slow }}$ pool enters $C_{\text {fast }}$ (Fig. 1b) based on a microbial efficiency of decomposition $\left(e_{\mathrm{d}_{2}}\right.$, Table 1 and Eq. 10) while the rest is emitted as part of the total soil respiration.

$$
\begin{aligned}
\frac{\mathrm{d} C_{\text {fast }}}{\mathrm{d} t} & =\left(1-f_{\text {lignin }}\right) \cdot e_{\mathrm{d}_{2}} \cdot t_{\mathrm{r}} \cdot k_{i} \cdot C_{L_{i}} \\
& +e_{\mathrm{d}_{2}} \cdot t_{\mathrm{r}} \cdot k_{\text {slow }} \cdot m_{\text {act }} \cdot C_{\text {microbes }} \\
& -k_{\mathrm{mc}} \cdot C_{\text {fast }} \cdot m_{\text {act }} \cdot C_{\text {microbes }},
\end{aligned}
$$

where $i=$ fol, root and wood for foliage, root and wood respectively. Together with carbon deposited to $C_{\text {fast }}$ from the first stage of decomposition, carbon is also allocated from $C_{\text {slow }}$ (Fig. 1b) after accounting for respiratory losses. Carbon is removed from the $C_{\text {fast }}$ pool by microbial uptake which depends on the size of $C_{\text {microbes }}$ and a constant rate for microbial carbon uptake $\left(k_{\mathrm{mu}}, \mathrm{m}^{2} \mathrm{~g} \mathrm{C}^{-1} \mathrm{~h}^{-1}\right)$ and microbial activity ( $m_{\text {act }}$, Eq. 10).

Microbial biomass (Eq. 11) grows each time step by consuming carbon from $C_{\mathrm{fast}}$ and is reduced by microbial death and by maintenance respiration.

$$
\begin{aligned}
\frac{\mathrm{d} C_{\text {microbes }}}{\mathrm{d} t} & =e_{\mathrm{u}} \cdot k_{\mathrm{mu}} \cdot C_{\mathrm{fast}} \cdot m_{\mathrm{act}} \cdot C_{\text {microbes }} \\
& -m_{\mathrm{c}} \cdot m_{\mathrm{act}} \cdot C_{\text {microbes }}-m_{\mathrm{d}} \cdot t_{\mathrm{r}} \cdot C_{\text {microbes }}
\end{aligned}
$$

Maintenance respiration is calculated as a portion of $C_{\text {microbes }}$ with a constant rate $\left(m_{\mathrm{c}}, \mathrm{h}^{-1}\right)$ limited by $m_{\text {act }}$ (Eq. 12). Respiration from soil decomposition $\left(R_{\mathrm{d}}\right.$, $\mathrm{g} \mathrm{C} \mathrm{m}^{-2} \mathrm{~d}^{-1}$ ) is the sum of respiration during decomposition of $C_{\text {slow }}$ and respiration during growth and maintenance of $C_{\text {microbes }}$ (Eq. 12 and Fig. 1b).

$$
\begin{aligned}
R_{\mathrm{d}} & =\left(1-e_{\mathrm{d}_{2}}\right) \cdot k_{\mathrm{slow}} \cdot t_{\mathrm{r}} \cdot C_{\text {microbes }} \\
& +\left(1-e_{\mathrm{u}}\right) \cdot k_{\mathrm{mc}} \cdot C_{\text {fast }} \cdot m_{\mathrm{act}} \cdot C_{\text {microbes }} \\
& +m_{\mathrm{c}} \cdot m_{\mathrm{act}} \cdot C_{\text {microbes }}
\end{aligned}
$$

Similar to the chemical model, total soil heterotrophic respiration is then calculated as the sum of soil decomposition and decomposition of the litter pools (Eq. 13).

$R_{\mathrm{S}}=R_{1}+R_{\mathrm{d}}$

\subsection{Parameterization and steady state}

Before running the numerical experiments the steady-state conditions for both models were explored. First, any temperature variation effect on decomposition was initially switched off in both models (i.e. the parameter adjusting the temperature rate was held constant at 1). The decomposition rates for the chemical model and biological models were tuned manually and were allowed to spin up for 1000 years. The process was repeated until pools were in steady state, with inputs equal to outputs. Then the mean residence time for each pool was calculated (MRT, years) as the ratio between the sum of fluxes out of the pool to the size of the pool (Eq. 14).

$\mathrm{MRT}=\frac{\sum \text { flux }_{\text {out }}}{C_{\text {pool }}}$

Decomposition rates and efficiency of decomposition of the first stage were calibrated to produce an MRT of 1,2 and 5 years for $C_{L_{\mathrm{f}}}, C_{L_{\mathrm{r}}}$ and $C_{L_{\mathrm{w}}}$ respectively. For the chemical model parameters were calibrated to produce an MRT of 10 and 100 years for $C_{\text {fast }}$ and $C_{\text {slow }}$ respectively. These MRTs are reasonable given incubation data (Schädel et al., 2013). For the biological model, parameters associated with the microbial activity, efficiency of microbial decomposition, microbial death and maintenance coefficients were extracted from literature (Blagodatsky et al., 1998, 2010, 2011). Decomposition rate of the slow SOC pool $\left(k_{\text {slow }}, \mathrm{h}^{-1}\right)$ and $f_{\text {lignin }}$ were calibrated separately for each model to ensure that the pool reached a reasonable steady state. In the second phase of calibration, we included diurnal and seasonal variation in temperature, using observations, and both models were allowed to spin up for another 1000 years to reach steady state. Results were summarized and MRTs for each pool of each model were calculated. We then calculated the sum over a single year for total soil respiration (sum $R_{\mathrm{S}}, \mathrm{g} \mathrm{C} \mathrm{m}^{-2} \mathrm{~d}^{-1}$ ) and total litter input (sum $L_{i}, \mathrm{~g} \mathrm{C} \mathrm{m}^{-2} \mathrm{~d}^{-1}$ ) for both models to confirm steady-state conditions.

\subsection{Parameter sensitivity analysis}

We performed a sensitivity analysis following the methodology described in Xenakis et al. (2008). The sensitivity was calculated for six outputs of the biological model (four state variables, $R_{\mathrm{d}}$ and $R_{\mathrm{S}}$ ) to the change of its 17 parameters, and four model outputs of the chemical model (two state variables, $R_{\mathrm{d}}$ and $R_{\mathrm{s}}$ ) to the change of 11 parameters. One parameter at a time was increased and decreased by $25 \%$ and the model run for 1000 years from a steady state. The relative sensitivity of each model output was then calculated as the relative change of the output to the relative change of the parameter (Eq. 15).

$\lambda=\frac{p}{X_{0}} \frac{X_{+}-X_{-}}{2 \delta p}$,

where $X_{0}$ is the model output with nominal parameters and $X_{+}$and $X_{-}$is the model output when the parameter was increased and decreased respectively. $p$ is the parameter value 
and $\delta p$ is the change of the parameter. The index $\lambda$ demonstrates the relation between the output and parameter as first derivative of their relationship, and shows the strength of the sensitivity of a model output to the parameter as well as the direction of the impact it will have. For example, a $\lambda$ of 0 indicates no sensitivity of the output to the parameter whereas a value close or greater than 1 indicates high sensitivity. A negative value of $\lambda$ indicates that an increase of the parameter decreased the output while a positive value indicates outputs increased with parameters.

\subsection{Numerical experiments}

We explored our hypotheses by running three numerical experiments using both models to allow an evaluation of the different sensitivities of the models to litter inputs and temperature forcing. For testing $\mathrm{H} 1$ we performed a litter change experiment and a carbon (glucose) addition experiment, and for $\mathrm{H} 2$ a temperature sensitivity experiment. All experiments were performed after ensuring models had reached a steady state. Carbon stocks for all pools including total soil carbon $\left(C_{\text {total }}, \mathrm{g} \mathrm{C} \mathrm{m}^{-2}\right), C_{\text {fast }}, C_{\text {slow }}$ and $C_{\text {microbes }}$ were plotted and MRT (years) calculated for all scenarios in each experiment. The percentage change (\%) of total soil respiration between the nominal and experiment scenarios was also calculated and plotted.

\subsubsection{Experiment 1 and 2: litter input and glucose addition}

Two related numerical experiments on litter additions were undertaken, with varying litter lability, for both models. In the first experiment we increased and decreased total litter input (i.e. similar increase for each of foliage, root and wood litter) by $25 \%$ of the nominal value and ran both models for 1000 years for all three scenarios (nominal, increased and decreased litter). This experiment tested sensitivity to a bulk change in plant litter production. In the second experiment we tested specifically for the effect of glucose exudation (i.e. inputs increased to $C_{\text {fast }}$, a change in litter quality and quantity), to test for the effects of priming. Starting from a steady state, we added $5 \mathrm{~g} \mathrm{C} \mathrm{m}^{-2}$ year $^{-1}$ (Blagodatsky et al., 2010), applied directly to $C_{\text {fast }}$ every time step, i.e. hour.

\subsubsection{Experiment 3: temperature sensitivity}

Both models were run for 1000 years from a steady state comparing two temperature scenarios (warming and cooling). Temperature data were obtained from the Arctic Biosphere Atmosphere Coupling at Multiple Scales (ABACUS) project (Street et al., 2013) for a dwarf birch site (Betula nana L.) located in Abisko, northern Sweden. Warming and cooling scenarios were developed by increasing and decreasing the measured hourly temperature by $2{ }^{\circ} \mathrm{C}$ respectively.

\section{Results}

\subsection{Model steady-state conditions}

The steady state for both models was tested by comparing the sum of total litter input and the sum of total soil respiration, with temperature variation switched on and off. We found that values closely matched after 1000 years (Table 2), with differences varying between 1.2 and $0.3 \%$ which we deemed an acceptable steady state. The calibration of the first stage of decomposition generated MRTs for the three litter pools of 1,2 and 5 years for foliage, root and wood respectively (Table 2). In the biological model turnover of $C_{\text {slow }}$ was slower compared to the chemical model, with a $20 \%$ larger MRT. However, in the biological model $C_{\text {fast }}$ MRT was nearly two orders of magnitude smaller than in the chemical model (Table 2), indicating a more rapid turnover.

For the biological model microbial biomass had an MRT $71 \%$ larger than $C_{\text {fast }}$. Including variable temperature reduced the MRT of the biological model by $5 \%$ for $C_{L_{\mathrm{f}}}, C_{L_{\mathrm{r}}}$ and $C_{L_{\mathrm{w}}}$ and by $1 \%$ for $C_{\mathrm{fast}}$ and increased MRT for $C_{\text {slow }}$ by $0.17 \%$. For the chemical model including variable temperature decreased MRT for all litter pools by $5 \%$ (Table 2 ).

Slow organic carbon stocks at steady state were $10 \%$ larger in the chemical model (Table 2). Fast organic carbon stocks were approximately 71 times smaller in the biological model. Together with the fast turnover (small MRT) these differences in stocks highlight the conceptual difference between the two models. In the case of the biological model, $C_{\text {fast }}$ represents a very short residence pool with carbon moving rapidly into the microbial pool. In the case of the chemical model, $C_{\text {fast }}$ represents the standard approach in soil carbon modelling, which is a pathway for carbon moving from litter to recalcitrant humus, with turnover faster than that of the slow pool.

\subsection{Sensitivity analysis}

Some important differences in the sensitivity of both $C_{\text {slow }}$ and $C_{\text {fast }}$ were observed between the two models (Fig. 2). In the biological model, $C_{\text {slow }}$ had very low sensitivity $(<0.1)$ in contrast to the chemical model, where $C_{\text {slow }}$ showed sensitivity to litter from foliage with $\lambda$ of 0.40 , from roots with $\lambda$ of 0.26 , and from wood with $\lambda$ of 0.19 . Litter inputs had also very low impact $(<0.1)$ on $C_{\text {fast }}$ in the biological model while in the chemical model $C_{\text {fast }}$ was found to be sensitive to inputs of foliage litter $(\lambda=0.48)$, roots $(\lambda=0.29)$ and wood $(\lambda=0.21)$.

$C_{\text {fast }}$ in the biological model was most sensitive to $m_{\mathrm{c}}$, $k_{\mathrm{mu}}, e_{\mathrm{u}}$ and $Q_{10}$, parameters related to maintenance respiration, the rate and efficiency of microbial carbon uptake and temperature effect on decomposition processes. $C_{\text {fast }}$ in the chemical model was most sensitive to $e_{\mathrm{d}_{1}}, k_{\text {fast }}$ and $f_{\text {lignin }}$, parameters related to the efficiency of litter decomposition, the fraction of lignin in litter and the decomposition rate. 
Table 2. Summary of the size of all carbon pools of the chemical and biological models including foliage litter $\left(C_{L_{\mathrm{f}}}, \mathrm{g} \mathrm{C} \mathrm{m}^{-2}\right)$, root litter $\left(C_{L_{\mathrm{r}}}, \mathrm{g} \mathrm{C} \mathrm{m}^{-2}\right)$, wood litter $\left(C_{L_{\mathrm{w}}}, \mathrm{g} \mathrm{C} \mathrm{m}^{-2}\right)$, fast soil carbon $\left(C_{\text {fast }}, \mathrm{g} \mathrm{C} \mathrm{m}^{-2}\right)$, slow soil carbon $\left(C_{\text {slow }}, \mathrm{g} \mathrm{C} \mathrm{m}^{-2}\right)$ and microbial biomass $\left(C_{\text {microbes }}, \mathrm{g} \mathrm{C} \mathrm{m}^{-2}\right)$ at the end of the 1000-year spin-up run, their respective mean residence time (MRT, years) and the sum over a single year of total soil respiration ( $\operatorname{sum} R_{\mathrm{S}}, \mathrm{g} \mathrm{C} \mathrm{m}^{-2}$ year $^{-1}$ ) and total litter input (sum $L_{i}, \mathrm{~g} \mathrm{C} \mathrm{m}^{-2}$ year $^{-1}$ ).

\begin{tabular}{|c|c|c|c|c|c|c|}
\hline & \multicolumn{3}{|c|}{ With no climate } & \multicolumn{3}{|c|}{ With climate } \\
\hline & Pool size & MRT & Total fluxes & Pool size & MRT & Total fluxes \\
\hline \multicolumn{7}{|l|}{ Chemical } \\
\hline$C_{L_{\mathrm{f}}}$ & 56.23 & 1.00 & & 53.33 & 0.95 & \\
\hline$C_{L_{\mathrm{r}}}$ & 68.65 & 2.00 & & 64.96 & 1.90 & \\
\hline$C_{L_{\mathrm{w}}}$ & 125.67 & 5.00 & & 118.84 & 4.74 & \\
\hline$C_{\text {fast }}$ & 359.68 & 10.00 & & 341.63 & 9.47 & \\
\hline$C_{\text {slow }}$ & 3865.87 & 100.00 & & 3756.86 & 94.76 & \\
\hline $\operatorname{sum} R_{\mathrm{S}}$ & & & 114.80 & & & 115.86 \\
\hline $\operatorname{sum} L_{i}$ & & & 116.26 & & & 116.23 \\
\hline \multicolumn{7}{|l|}{ Biological } \\
\hline$C_{L_{\mathrm{f}}}$ & 56.23 & 1.00 & & 53.33 & 0.95 & \\
\hline$C_{L_{\mathrm{r}}}$ & 68.65 & 2.00 & & 64.96 & 1.90 & \\
\hline$C_{L_{\mathrm{w}}}$ & 125.81 & 5.00 & & 118.84 & 4.74 & \\
\hline$C_{\text {fast }}$ & 5.08 & 0.14 & & 5.02 & 0.14 & \\
\hline$C_{\text {slow }}$ & 3485.60 & 119.43 & & 3485.26 & 119.63 & \\
\hline$C_{\text {microbes }}$ & 5.50 & 0.24 & & 5.55 & 0.24 & \\
\hline $\operatorname{sum} R_{\mathrm{S}}$ & & & 116.09 & & & 115.97 \\
\hline $\operatorname{sum} L_{i}$ & & & 116.28 & & & 116.28 \\
\hline
\end{tabular}

The sensitivity of $C_{\text {slow }}$ in the chemical model was linked to $k_{\text {slow }}, f_{\text {lignin }}$ and $e_{\mathrm{d}_{1}}$, parameters which determine the rate of decomposition, the fraction of lignin which gives the fraction of decomposed carbon that is directly deposited to the pool and the efficiency of litter decomposition. $C_{\text {slow }}$ in the biological model was sensitive to $k_{\text {slow }}, f_{\text {lignin }}, e_{\mathrm{u}}, m_{\mathrm{d}_{i}}, k_{\mathrm{mu}}$, $m_{\mathrm{c}}$ and $m_{\mathrm{d}_{x}}$, which control processes related to the efficiency of carbon uptake by microbes, maintenance respiration and microbial death.

Sensitivity of $R_{\mathrm{S}}$ and $R_{\mathrm{d}}$ to litter were the same for the two models. $R_{\mathrm{S}}$ was most sensitive to foliage $(\lambda=0.49)$, having slightly lower sensitivity to root litter $(\lambda=0.30)$, with a similar pattern for the chemical model. Respiration due to soil decomposition was most sensitive to foliage litter input with $\lambda$ of 0.24 , followed by root litter $(\lambda=0.15)$ and wood litter input $(\lambda=0.11)$. There was a similar pattern for the chemical model.

$C_{\text {microbes }}$ also showed high sensitivity to $m_{\mathrm{d}_{x}}, f_{\text {lignin }}, k_{\mathrm{mu}}$, $m_{\mathrm{d}_{i}}, e_{\mathrm{d}_{1}}$ and $m_{\mathrm{c}}$, parameters related to microbial death, efficiency of decomposition and rate of carbon uptake by the microbial biomass. The sensitivity analysis of the biological model showed a high sensitivity of the microbial biomass to foliage litter input $(\lambda=0.47)$ and a much lower sensitivity to roots $(\lambda=0.29)$ and wood $(\lambda=0.21)$. This sensitivity of $C_{\text {microbes }}$ to foliage, root and wood litter inputs can be explained by the rate of decomposition of each litter pool. The highest sensitivity is related to the litter with the higher decomposition rate (foliage) and vice versa (wood).
Comparing the sensitivities of the two models, we found that the introduction of a microbial pool buffered the sensitivity of other carbon pools to the amount of input litter. It did however introduce extra sensitivity to parameters related to microbial dynamics. Total soil respiration at steady state was found to be relatively insensitive to parameters related to microbial activity. Respiration of soil decomposition was found to be sensitive to the efficiency of decomposition of the first stage for both the biological $(\lambda=0.5)$ and chemical model $(\lambda=0.45)$.

\subsection{Litter quantity manipulation}

\subsubsection{Chemical model}

In the chemical model, the response of $C_{\text {fast }}$ was more significant in magnitude than the biological case, but slower, reaching a maximum change in $C_{\text {fast }}$ stocks of $\pm 25 \%$ by year 75 for both litter scenarios (Fig. 3b). Unlike the biological model, MRT remained unchanged at approximately 9 years (Table 3). The response of $C_{\text {slow }}$ was found to have a maximum change of $25 \%$ after 1000 years for both scenarios. Again, unlike the biological model, the MRT of $C_{\text {slow }}$ was unchanged. Total SOC response was similar to that of $C_{\text {slow }}$. Total soil respiration approached a steady state towards the end of the 1000 years of simulation, with a final change of $25 \%$ for both litter scenarios (Fig. 4a). 

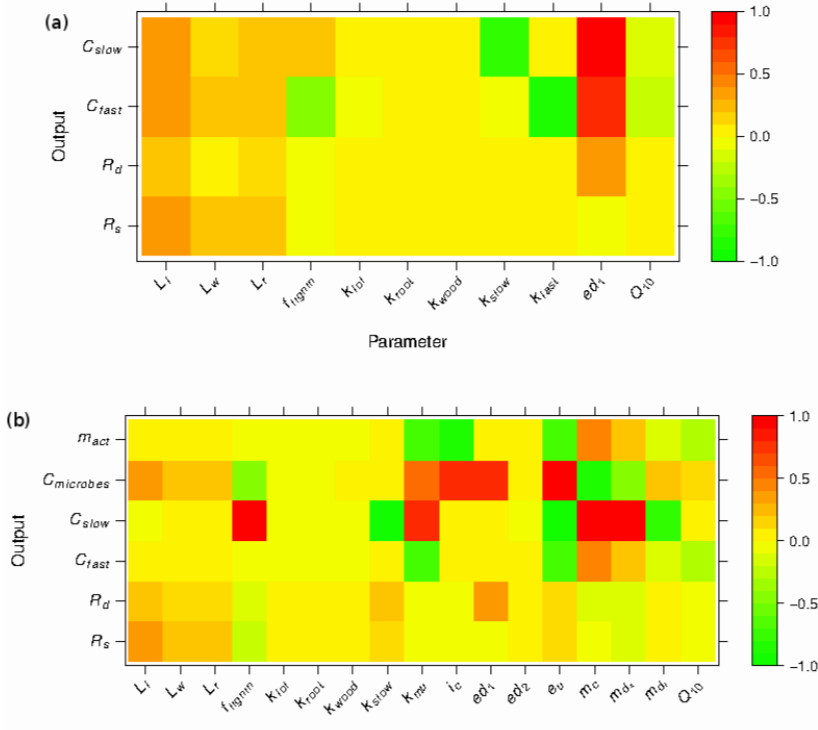

Parameter

Figure 2. Sensitivity of the two models to their respective parameters. Outputs tested were all three soil carbon pools including $C_{\text {fast }}$ and $C_{\text {slow }}$ for (a) the chemical model and fast $\left(C_{\text {fast }}\right.$, $\left.\mathrm{g} \mathrm{C} \mathrm{m}^{-2}\right)$, slow $\left(C_{\text {slow }}, \mathrm{g} \mathrm{C} \mathrm{m}^{-2}\right)$ and microbial pool $\left(C_{\text {microbes }}\right.$, $\mathrm{g} \mathrm{C} \mathrm{m}^{-2}$ ) for (b) the biological model. Also the sensitivity of three respiration fluxes were tested including total soil respiration $\left(R_{\mathrm{S}}\right.$, $\left.\mathrm{g} \mathrm{C} \mathrm{m}^{-2} \mathrm{~d}^{-1}\right)$, litter respiration $\left(R_{1}, \mathrm{~g} \mathrm{C} \mathrm{m}^{-2} \mathrm{~d}^{-1}\right)$ and respiration from soil decomposition $\left(R_{\mathrm{d}}, \mathrm{g} \mathrm{C} \mathrm{m}^{-2} \mathrm{~d}^{-1}\right)$ for both models. Model sensitivity was calculated using the method by Xenakis et al. (2008). Values close to or greater than -1 and 1 show high negative and positive sensitivity respectively. For all symbol explanations, see Table 1 .

\subsubsection{Biological model}

$C_{\text {microbes }}$ responded rapidly to changes in litter quantity, reaching steady values within 30 years, increasing by $19 \%$ for the $25 \%$ rise in litter and declining by $39 \%$ for the $25 \%$ decline in litter (Fig. 3g). The change in MRT at steady state was small for both litter scenarios $(0.72$ and $1.15 \%)$ remaining at 0.25 years (Table 3 ).

$C_{\text {fast }}$ also responded rapidly to changes in litter, but the magnitude of change was much lower than for $C_{\text {microbes }}$. When litter was increased by $25 \%$ the pool reached its maximum response with the first 2 years, initially increasing by $2 \%$ and later returning close to its original steady value after $\sim 14$ years. When litter was reduced by $25 \%$ there was a similar, although negative response for the first 2 years but with a decline of $2.2 \%$. The pool returned to the original steady state after 24 years (Fig. 3e).

Because of the small change to the $C_{\text {fast }}$ carbon stock with a change in throughput, its MRT declined by $20 \%$ with $25 \%$ litter increase and increased by $33 \%$ for $25 \%$ litter decrease (Fig. $3 \mathrm{f}$ ). $C_{\text {slow }}$ on the other hand responded very slowly to changes in litter. There was only a $0.03 \%$ change in stocks after 10 years for both scenarios. No steady state was reached
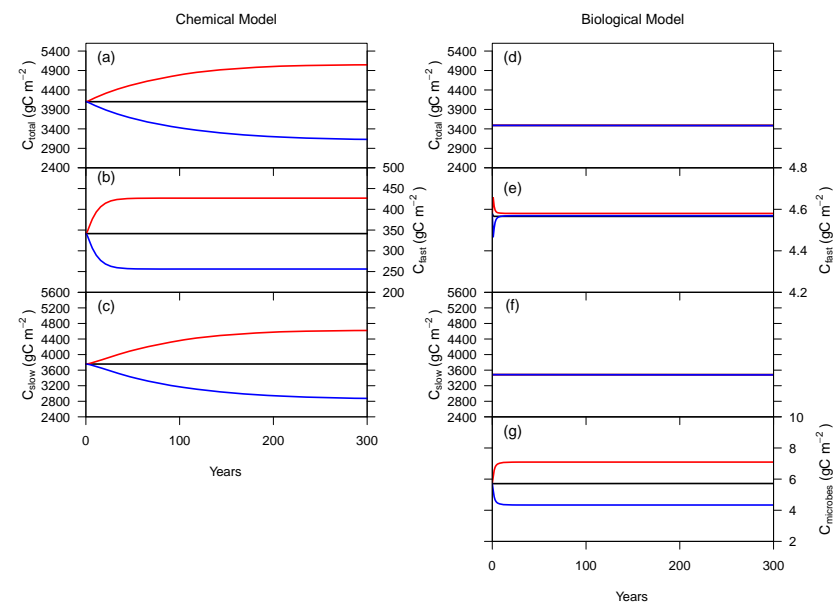

Figure 3. Soil carbon stocks of the chemical and biological models for the litter quantity experiments. (a) is the total soil carbon $\left(C_{\text {total }}, \mathrm{g} \mathrm{C} \mathrm{m}^{-2}\right)$, (b) fast pool $\left(C_{\text {fast }}, \mathrm{g} \mathrm{C} \mathrm{m}^{-2}\right)$, (c) slow pool $\left(C_{\text {slow }}, \mathrm{g} \mathrm{C} \mathrm{m}^{-2}\right)$ of the chemical model, (d) is the total soil carbon $\left(C_{\text {total }}, \mathrm{g} \mathrm{C} \mathrm{m}^{-2}\right)$, (e) fast pool $\left(C_{\text {fast }}, \mathrm{g} \mathrm{C} \mathrm{m}^{-2}\right)$, (f) slow pool $\left(C_{\text {slow }}, \mathrm{g} \mathrm{C} \mathrm{m}^{-2}\right)$ and $(\mathrm{g})$ microbial biomass $\left(C_{\text {microbes }}, \mathrm{g} \mathrm{C} \mathrm{m}^{-2}\right)$ of the biological model. Black line shows the nominal run, red line the increased litter and blue the decrease litter scenario. Only the first 300 years of the simulation are shown.

after 1000 years, with a $0.56 \%$ increase over that period for the decrease scenario and a $0.29 \%$ decrease for the increase scenario.

Increasing litter inputs reduced MRT of $C_{\text {slow }}$ by $20 \%$ after 1000 years (Table 3), associated with an insignificant change in $\mathrm{C}$ stocks. A decrease in litter slowed turnover of $C_{\text {slow }}$ by $33 \%$ after 1000 years. The initial response of the microbial activity (data not shown) after the first year increased by $1.9 \%$ for increased litter and decreased by $2.2 \%$ for the decreased litter scenario. After 15 years the response of microbial activity to litter fell to $0.42 \%$ for the increasedlitter scenario and led to a very insignificant change $(0.01 \%)$ for the decreased scenario, until the end of the simulation. $C_{\text {total }}$ response was similar to that of $C_{\text {slow }}$ because of the relative size difference between the slow and fast pool. Total soil respiration was found to have a sharp change from its nominal condition reaching its maximum change of $25 \%$ within 35 years for both litter scenarios (Fig. 4a).

\subsection{Litter quality manipulation}

\subsubsection{Chemical model}

The extra $5 \mathrm{~g} \mathrm{C} \mathrm{m}^{-2}$ year $^{-1}$ added to $C_{\text {fast }}$ caused a gradual increase of the pool in the chemical model, with a new steady state $14 \%$ larger achieved by year 84 (Fig. 5b). This increased stock was linked to a slower turnover rate, with the MRT doubling (Table 3). $C_{\text {slow }}$ increased even more slowly, rising by $6 \%$ by the end of the 1000 -year simulation with 

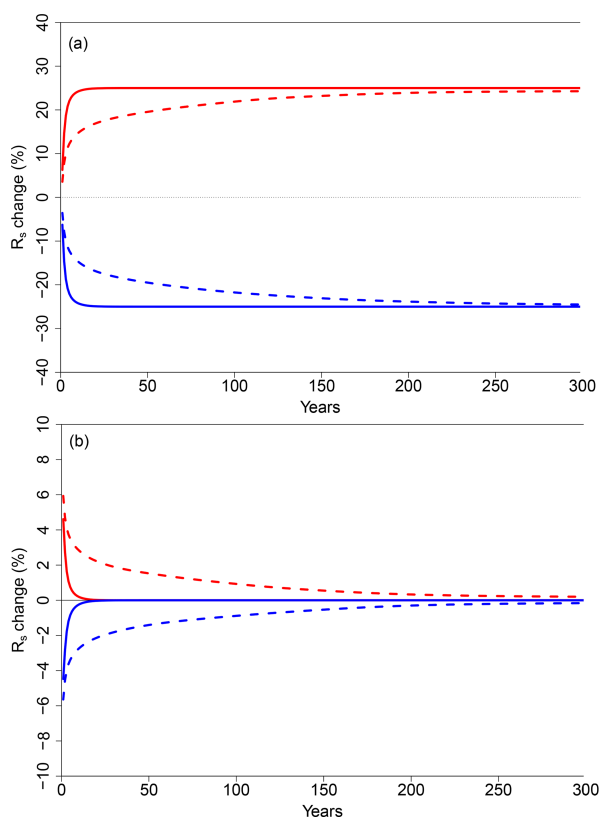

Figure 4. The percentage change $(\%)$ of total soil respiration between the nominal and increased litter (red lines) and the nominal and decreased litter (blue lines) for (a) the litter quantity manipulation experiment and (b) the temperature manipulation experiment. Solid lines are for the biological and dashed lines for the chemical model. Only the first 300 years of the simulation are shown.

MRT remaining unchanged. The overall response was an increase in total carbon stored in the soil pools (Fig. 5a).

\subsubsection{Biological model}

Changing the quality of litter by adding $5 \mathrm{~g} \mathrm{C} \mathrm{m}^{-2}$ year $^{-1}$ of extra glucose exudation directly to the fast soil organic carbon pool (i.e. priming) had a great impact on the size and MRT of $C_{\text {slow }}$ (Fig. 5f). By the end of the 1000-year simulation $C_{\text {slow }}$ was still declining, with a total reduction of $87 \%$. $C_{\text {slow }}$ MRT declined by $89 \%$ (Table 3 ). $C_{\text {microbes }}$ increased by $12 \%$ within 1 year of the start of the simulation and remained at this new steady state for the rest of the simulation (Fig. $5 \mathrm{~g}$ ). However, the change in $C_{\text {microbes }}$ MRT was very small $(0.93 \%)$. $C_{\text {fast }}$ although receiving directly the added glucose exudate only increased slightly by $2 \%$ in the first year and then settled to a steady-state change of $1 \%$. Its MRT, however, was reduced by $11 \%$. Microbial activity responded by an initial increase of $2 \%$, dropping to a steadystate change of $1 \%$. The overall response was a continuing and major decline over the 1000-year experiment in total C stocks in soil (Fig. 5d).

\subsection{Temperature manipulation}

\subsubsection{Chemical model}

Response of $C_{\text {fast }}$ in the chemical model was significantly different from that of the biological. Warming reduced the pool by $7 \%$ within 65 years while cooling caused an increase in carbon by $7 \%$ again within the same period (Fig. 6b), in both cases reaching new steady states. MRT was reduced by $6 \%$ by warming and increased by $7 \%$ by cooling (Table 3 ). $C_{\text {slow }}$ responded to the change with a decrease in stocks by the end of the 1000-year simulation of $6 \%$ with warming and an increase by $7 \%$ with cooling. MRT of $C_{\text {slow }}$ was reduced by $6 \%$ with warming and increased by $7 \%$ with cooling. The overall response of $\mathrm{C}$ stocks (Fig. 6a) was $6 \%$ for the warming and $7 \%$ for the cooling scenario over the 1000-year period. Total soil respiration increased by $6 \%$ for the warming and decreased by $6 \%$ for the cooling scenario, but it only returned to its original value towards the end of the simulation, at $\sim 1000$ years (Fig. $4 b$ ).

\subsubsection{Biological model}

$C_{\text {microbes }}$ responded to temperature change with an initial increase of $4 \%$ in the warming and decrease of $4 \%$ in the cooling scenario. But within 3 years stocks returned close to their initial values in both cases (Fig. 6g). The MRT of $C_{\text {microbes }}$ remained unchanged at 0.25 years at their new steady states, for both the increased and decreased temperature numerical experiments. After an initial $0.30 \%$ response to warming/cooling, $C_{\text {fast }}$ then returned to its original steadystate value within a few years (Fig. 6e). The change in MRT of $C_{\text {fast }}$ with both scenarios was insignificant: $0.05 \%$ and $0.06 \%$ for warming and cooling respectively (Fig. $6 \mathrm{~g}$ ).

$C_{\text {slow }}$ responded very slowly to the change and had not reached a steady state after 1000 years. Both scenarios caused a decrease in $\mathrm{C}$ stocks over the 1000-year period reaching a change of $0.06 \%$ for the warming and $0.04 \%$ for the cooling scenario. Microbial activity was decreased by $0.3 \%$ the first year for the warming scenario and increased by the same percentage for the cooling scenario, but returned to its initial values by year 10 . The overall response of $\mathrm{C}$ stocks (Fig. 6d) by the end of the 1000-year simulation was a decrease by $0.06 \%$ for the warming and an increase by $0.04 \%$ for the cooling scenario. Total respiration increased the first year by $5 \%$ for the warming and decreased by $4.5 \%$ for the cooling scenario (Fig. 4b) and then returned to the original steady-state value within 20 years.

\section{Discussion}

The numerical experiments highlight the key difference between the models. For changes in litter inputs, MRT adjusts in the biological model to buffer changes to $C_{\text {slow }}$. However, MRT is unchanged in the chemical model leading to 
Table 3. Summary of all three experiment and nominal runs for both the biological and chemical models. For each carbon pool, including foliage litter $\left(C_{L_{\mathrm{f}}}, \mathrm{g} \mathrm{C} \mathrm{m}^{-2}\right)$, root litter $\left(C_{L_{\mathrm{r}}}, \mathrm{g} \mathrm{C} \mathrm{m}^{-2}\right)$, wood litter $\left(C_{L_{\mathrm{w}}}, \mathrm{g} \mathrm{C} \mathrm{m}^{-2}\right)$, fast soil carbon $\left(C_{\mathrm{fast}}, \mathrm{g} \mathrm{C} \mathrm{m}^{-2}\right)$, slow soil carbon $\left(C_{\text {slow }}, \mathrm{g} \mathrm{C} \mathrm{m}^{-2}\right)$ and microbial biomass $\left(C_{\text {microbes }}, \mathrm{g} \mathrm{C} \mathrm{m}^{-2}\right)$, the size of the pool at the end of the 1000-year run, the mean residence time (MRT, years) and the percentage change (\%) of MRT between the nominal and experiment run are given. The table also presents the sum of fluxes over a single year's simulation of total soil respiration ( $\operatorname{sum} R_{\mathrm{S}}, \mathrm{g} \mathrm{C} \mathrm{m}^{-2}$ year ${ }^{-1}$ ) and total litter input (sum $L_{i}, \mathrm{~g} \mathrm{C} \mathrm{m}^{-2} \mathrm{year}^{-1}$ ).

\begin{tabular}{|c|c|c|c|c|c|c|c|c|c|c|c|c|c|c|c|}
\hline & \multicolumn{11}{|c|}{ Litter quantity } & \multirow{2}{*}{\multicolumn{4}{|c|}{$\begin{array}{c}\text { Litter quality } \\
\text { Increase }\end{array}$}} \\
\hline & \multicolumn{3}{|c|}{ Nominal } & \multicolumn{4}{|c|}{ Increase } & \multicolumn{4}{|c|}{ Decrease } & & & & \\
\hline & Pool size & MRT & Total fluxes & Pool size & MRT & Total fluxes & $\%$ change & Pool size & MRT & Total fluxes & $\%$ change & Pool size & MRT & Total fluxes & $\%$ change \\
\hline \multicolumn{16}{|l|}{ Chemical } \\
\hline$C_{L_{\mathrm{f}}}$ & 52.45 & 0.93 & & 65.56 & 0.93 & & & 39.34 & 0.93 & & 0.01 & 52.45 & 0.93 & & \\
\hline$C_{L_{\mathrm{r}}}$ & 64.30 & 1.87 & & 80.38 & 1.87 & & & 48.23 & 1.87 & & & 64.30 & 1.87 & & \\
\hline$C_{L_{\mathrm{w}}}$ & 118.30 & 4.70 & & 147.87 & 4.70 & & 0.01 & 88.73 & 4.70 & & & 118.30 & 4.70 & & \\
\hline$C_{\text {fast }}$ & 341.46 & 9.44 & & 426.89 & 9.44 & & -0.01 & 256.12 & 9.44 & & -0.01 & 388.71 & 18.87 & & 99.94 \\
\hline$C_{\text {slow }}$ & 3761.44 & 94.42 & & 4646.28 & 94.43 & & & 2847.83 & 94.42 & & & 3996.53 & 94.42 & & \\
\hline $\operatorname{sum} R_{\mathrm{S}}$ & & & 115.91 & & & 144.30 & & & & 87.21 & & & & 120.90 & \\
\hline $\operatorname{sum} L_{i}$ & & & 115.96 & & & 144.95 & & & & 86.97 & & & & 120.97 & \\
\hline \multicolumn{16}{|l|}{ Biological } \\
\hline$C_{L_{\mathrm{f}}}$ & 52.45 & 0.93 & & 65.56 & 0.93 & & & 39.34 & 0.93 & & & 52.45 & 0.93 & & \\
\hline$C_{L_{\mathrm{r}}}$ & 64.30 & 1.87 & & 80.38 & 1.87 & & & 48.23 & 1.87 & & & 64.30 & 1.87 & & \\
\hline$C_{L_{\mathrm{W}}}^{L_{\mathrm{T}}}$ & 118.30 & 4.70 & & 147.88 & 4.70 & & & 88.73 & 4.70 & & & 118.30 & 4.70 & & \\
\hline$C_{\text {fast }}$ & 4.57 & 0.12 & & 4.58 & 0.10 & & -19.75 & 4.57 & 0.17 & & 33.44 & 4.64 & 0.11 & & -10.83 \\
\hline$C_{\text {slow }}$ & 3485.10 & 119.28 & & 3474.95 & 95.15 & & -20.23 & 3465.49 & 158.14 & & 32.58 & 445.48 & 13.39 & & -88.78 \\
\hline$C_{\text {microbes }}$ & 5.72 & 0.25 & & 7.09 & 0.25 & & -0.72 & 4.34 & 0.25 & & 1.15 & 6.45 & 0.25 & & -0.93 \\
\hline sum $R_{\mathrm{S}}$ & & & 115.97 & & & 144.96 & & & & 86.98 & & & & 124.01 & \\
\hline $\operatorname{sum} L_{i}$ & & & 115.96 & & & 144.95 & & & & 86.97 & & & & 120.97 & \\
\hline
\end{tabular}

Table 3. Continued.

\begin{tabular}{|c|c|c|c|c|c|c|c|c|}
\hline & \multicolumn{8}{|c|}{ Temperature change } \\
\hline & \multicolumn{4}{|c|}{ Increase } & \multicolumn{4}{|c|}{ Decrease } \\
\hline & Pool size & MRT & Total fluxes & $\%$ change & Pool size & MRT & Total fluxes & $\%$ change \\
\hline \multicolumn{9}{|l|}{ Chemical } \\
\hline$C_{L_{\mathrm{f}}}$ & 49.02 & 0.87 & & -6.54 & 56.13 & 1.00 & & 7.01 \\
\hline$C_{L_{\mathrm{r}}}$ & 60.09 & 1.75 & & -6.56 & 68.81 & 2.00 & & 7.02 \\
\hline$C_{L_{\mathrm{w}}}$ & 110.57 & 4.39 & & -6.53 & 126.57 & 5.03 & & 6.99 \\
\hline$C_{\text {fast }}$ & 319.21 & 8.82 & & -6.52 & 365.22 & 10.09 & & 6.97 \\
\hline$C_{\text {slow }}$ & 3525.39 & 88.28 & & -6.51 & 4015.52 & 101.00 & & 6.96 \\
\hline $\operatorname{sum} R_{\mathrm{S}}$ & & & 116.00 & & & & 115.83 & \\
\hline $\operatorname{sum} L_{i}$ & & & 115.96 & & & & 115.96 & \\
\hline \multicolumn{9}{|l|}{ Biological } \\
\hline$C_{L_{\mathrm{f}}}$ & 49.02 & 0.87 & & -6.55 & 56.13 & 1.00 & & 7.01 \\
\hline$C_{L_{\mathrm{r}}}$ & 60.09 & 1.75 & & -6.56 & 68.81 & 2.00 & & 7.02 \\
\hline$C_{L_{\mathrm{W}}}$ & 110.57 & 4.39 & & -6.53 & 126.57 & 5.03 & & 6.99 \\
\hline$C_{\text {fast }}$ & 4.56 & 0.12 & & -0.02 & 4.57 & 0.12 & & 0.02 \\
\hline$C_{\text {slow }}$ & 3483.14 & 119.21 & & -0.06 & 3486.65 & 119.34 & & 0.05 \\
\hline$C_{\text {microbes }}$ & 5.71 & 0.25 & & -0.07 & 5.72 & 0.25 & & 0.06 \\
\hline $\operatorname{sum} R_{\mathrm{S}}$ & & & 115.97 & & & & 115.97 & \\
\hline $\operatorname{sum} L_{i}$ & & & 115.96 & & & & 115.96 & \\
\hline
\end{tabular}

significant adjustments in $C_{\text {total }}$. For changes in temperature, MRT is insensitive in the biological model, again buffering changes in $C_{\text {total }}$; in the chemical model MRT responds, leading to significant adjustments to $C_{\text {total }}$. Only for changes in litter quality, i.e. priming, does the biological model have greater sensitivity in $C_{\text {slow }}$ than in the chemical model.
H1. Litter inputs and glucose additions will prime microbial activity and reduce SOC stocks in the biological model, but will increase SOC stocks in the chemical model

Our results (Fig. 3) provided some support for this hypothesis. Increasing total litter input into the ecosystem primed 


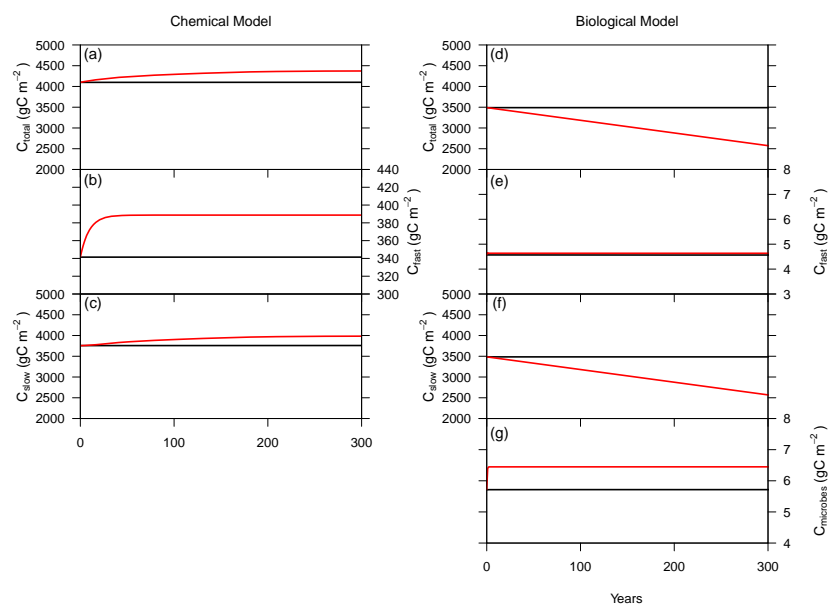

Figure 5. Soil carbon stocks of the chemical and biological models for the litter quality experiments. (a) is the total soil carbon $\left(C_{\text {total }}, \mathrm{g} \mathrm{C} \mathrm{m}^{-2}\right)$, (b) fast pool $\left(C_{\text {fast }}, \mathrm{g} \mathrm{C} \mathrm{m}^{-2}\right)$ and (c) slow pool $\left(C_{\text {slow }}, \mathrm{g} \mathrm{C} \mathrm{m}^{-2}\right)$, of the chemical model, (d) is the total soil carbon $\left(C_{\text {total }}, \mathrm{g} \mathrm{C} \mathrm{m}^{-2}\right)$, (e) fast pool $\left(C_{\text {fast }}, \mathrm{g} \mathrm{C} \mathrm{m}^{-2}\right)$, f) slow pool $\left(C_{\text {slow }}, \mathrm{g} \mathrm{C} \mathrm{m}^{-2}\right)$ and $(\mathrm{g})$ microbial biomass $\left(C_{\text {microbes }}, \mathrm{g} \mathrm{C} \mathrm{m}^{-2}\right)$ of the biological model. Black lines show runs with no addition and red lines with addition of glucose exudates. Only the first 300 years of the simulation are shown.

microbial activity in the biological model by increasing microbial biomass and thus reducing old carbon $\left(C_{\text {slow }}\right)$ MRTs.

The biological model reached its new steady state more rapidly than the chemical model in response to changes in litter quality. Thus, litter changes in the biological model led to more rapid responses in respiration than in a typical chemically based system (Fig. 4). The change in respiration between the two models after they reached their new steady state was not very different, but the timing differences were significant (Fig. 4a), so there are important differences between long-term and short-term effects. The ecological implication is that a biological model will have a more rapid response of soil respiration in the early years of the added carbon, with a more immediate effect. In a more realistic case with litter added as pulses rather than continuously, this might mean higher peaks in respiration fluxes with the beginning of senescence.

Schmidt et al. (2011) proposed that fresh root inputs will prime microbial activity. The sensitivity analysis (Fig. 2) indicated that an increase in root litter would increase microbial biomass and thus provide a larger microbial community which when active will prime old organic carbon. However, we found that fresh foliage litter will have an even larger impact on microbial biomass probably due to the high sensitivity of the microbes to the lignin fraction (Fig. 2b). Our observed microbial priming from root and foliage litter can also explain the hypothesis suggested by Hartley et al. (2012) that Arctic plant growth has a positive priming on soil carbon, reducing old organic carbon, and can also support their observations of changing soil carbon stocks at the transition from low Arctic tundra vegetation to birch forest. When birch starts to substitute tundra, we can hypothesize that a larger input of labile carbon arises because of higher production and a shift to deciduous, thinner leaves, which primes microbial activity.

For the biological model, the large decline in $C_{\text {slow }}$ in response to glucose addition over 1000 years and the lack of a new steady state developing (Fig. 5), is noteworthy. The sustained increase in microbial biomass resulting from priming with glucose allows a continual and constant increased decomposition rate of $C_{\text {slow }}$ (Fig. 5f). The biological model is missing any feedback processes that might result in a new steady state, for instance physical protection of some fraction of $C_{\text {slow }}$. Also, increased decomposition, leading to mineralization of $\mathrm{N}$, is likely to increase woody fraction of litterfall as plant production rises. This lignification of litter should adjust decomposition over time. Further model development is required to evaluate these feedbacks.

Adding extra labile carbon (glucose) directly into the biological system increased microbial carbon consumption from $C_{\text {fast }}$, increased $C_{\text {microbes }}$, primed microbial activity and increased the decomposition of $C_{\text {slow }}$ (Fig. 5). Microbial priming is a tested concept in short-term incubation studies (Blagodatsky et al., 1998, 2010). Although evidence of the impact of microbial activity and priming on decomposition has started to appear in the literature (Turetsky et al., 2008; Allison et al., 2010; Hartley et al., 2012; Frey et al., 2013), very little is known about the longer-term impact on carbon stocks. The importance of considering alternatives to the typical chemically based model is demonstrated by the impact the microbial community dynamics has on old organic carbon after the addition of extra labile carbon. Our biological model showed that a small increase of $13 \%$ to $C_{\text {microbes }}$ reduced the turnover time of the old carbon pool by almost 106 years and significantly reduced total soil carbon stocks by $87 \%$ over 1000 years.

Introducing microbial dynamics created some very interesting feedbacks to $C_{\text {fast }}$ and $C_{\text {slow }}$. Both pools were found to be buffered against any changes in litter quantity with unchanged carbon stocks and a reduction in the MRTs (Table 3). In contrast, the chemical model MRT of both $C_{\text {fast }}$ and $C_{\text {slow }}$ remained the same but with a significant change to their C stocks (Fig. 3). We suggest the buffering of SOC was due to the introduction of microbial activity, which accelerated the turnover of new $\mathrm{C}$ introduced by litter, increased respiration rapidly (Fig. 4) and consumed the rest for microbial biomass growth (Table $3 \mathrm{~d}$ ), keeping $C_{\text {slow }}$ and $C_{\text {fast }}$ unchanged. Further model experiments are required to investigate the effect of seasonal cycles in litter inputs.

Comparing the sensitivity of the biological and chemical model, we found that introducing microbial activity removed the sensitivity of $C_{\text {fast }}$ and $C_{\text {slow }}$ to litter inputs (Fig. 2) but introduced significant sensitivity to parameters related to either growth or death of microbial biomass. The buffering of 
SOC in the biological model is once again apparent as microbial priming will rapidly consume carbon coming from litter inputs and thus leave the soil pools unaffected. We found, however, that $C_{\text {microbes }}$ was quite sensitive to litter input and in particular to foliage litter because it is the biggest influx of carbon and foliage has the highest decomposition rate (Table 1). Further numerical experiments are necessary to explore the impact of the decomposition rates on microbial priming. $C_{\text {microbes }}$ was found also to be highly sensitive to the fraction of lignin, a parameter related to litter quality. In the biological model the carbon consumed by microbes comes from the labile $C_{\text {fast }}$ pool and thus has a preference for litter with low lignin content. Higher concentrations of lignin in litter will reduce or remove microbial priming. For our study, $f_{\text {lignin }}$ was calibrated and chosen to be similar for each litter type, to ensure a steady-state condition and simplify the analysis, resulting in a value larger than expected from literature (Chapin et al., 1986), which may have enhanced the impact of microbial priming. Also, different plants in Arctic ecosystems were found to have different seasonal patterns of lignin concentration in their foliage, stem and roots (Chapin et al., 1986). For example Chapin et al. (1986) found that the fraction of lignin for birch in the Alaskan tundra was between 0.05 and 0.15 for leaves from July to August and 0.25 and 0.18 for roots for the same period. Seasonal variability of lignin is likely to affect the timing of microbial priming. Further numerical experiments are needed to explore further the impact of different lignin fractions in different vegetation parts (i.e. foliage, root and wood) taking seasonal variation into account, closely linked to field data.

\section{H2. Warming will stimulate decomposition in the chemical model and loss of SOC, but the SOC in the biological model will be less sensitive to warming due to complex interactions between SOC and the microbial pool}

Our results (Fig. 6) support the hypothesis. The first-order representation of temperature on the chemical model kinetics caused a loss of SOC with warming. In the biological model SOC was buffered from climate change by microbial dynamics. For the biological model we assumed microbial activity was directly affected by temperature (Eq. 7), and thus processes that are linked to microbial activity are indirectly affected by temperature.

Microbial death is also related to first-order kinetics through temperature (Eq. 11). Warming increased microbial death, reducing microbial biomass and thus reducing microbial activity making decomposition less sensitive to temperature. These indirect and compensating effects on microbial activity and biomass explain why SOC appears less sensitive to temperature effects in the biological model.

There is recent evidence that temperature change will affect the efficiency with which carbon is converted to microbial biomass (Melillo et al., 2002; Allison et al.,
2010; Wetterstedt and Ågren, 2011; Frey et al., 2013). Allison et al. (2010) found the response of soil carbon to climate depends on the efficiency of microbial biomass in using carbon, linking the resilience in both soil respiration and soil carbon with warming to a decline in microbial biomass and degradation of enzymes. We also found the biological model produced a drop in soil respiration after an increase of $5 \%$ in the first year of warming (data not shown), returning to its original steady-state value after 20 years (Fig. 4b). Allison et al. (2010) suggest that enzymatic acclimation will produce less respiration in the first years of warming and the drop will be smoother. This is a process which is currently missing from our model but if included could possibly make it even less sensitive to temperature.

For any further development to include enzymatic acclimation, the model will also have to consider the impact of litter quality on microbial efficiency. Frey et al. (2013) showed microbial efficiency dependency on both temperature and quality of the substrate decomposed, with microbial efficiency dropping for more refractory material under warm conditions. They found temperature had insignificantly affected microbial efficiency of glucose decomposition, attributing this to glucose not requiring extracellular enzymatic breakdown. They also showed microbial efficiencies had a narrow range of between 70 and $75 \%$. We calculated microbial efficiency for our biological model as the ratio of the total flux between $C_{\text {fast }}$ and $C_{\text {microbes }}$ minus growth respiration to the total flux between the two pools. We found that efficiency remained unchanged at $63 \%$ with either increase or decrease of temperature. Wetterstedt and Ågren (2011) have used a microbial decomposition related to temperature in a modelling study, but they also included a dependency on litter quality. In an incubation experiment, they used two different litter qualities with different lability and found that the higher-quality litter had a greater contribution to soil respiration than the lower-quality one. Including both temperature and difference in litter quality, their model showed greater sensitivity in respiration rates and SOC dynamics. In our model, we considered only temperature effects (Eq. 7). The lack of any direct impact of litter quality on microbial activity might have significantly reduced the sensitivity of temperature to decomposition. Further development of the biological model should consider including decomposition of other substrates and making microbial activity dependent on both temperature and litter quality.

The biological model was also able to replicate the findings by Luo et al. (2001), who showed soil respiration acclimatized to temperature; that is, temperature sensitivity of soil respiration was reduced when exposed to warming. They suggest acclimatization occurred because of changes to the microbial community which reduced the respiratory capacity of the soil. We found the increase in microbial biomass with warming (Fig. 6g) corresponded with the increase in soil respiration. Respiration initially increased due to increased microbial biomass which boosted decomposition. As microbial 

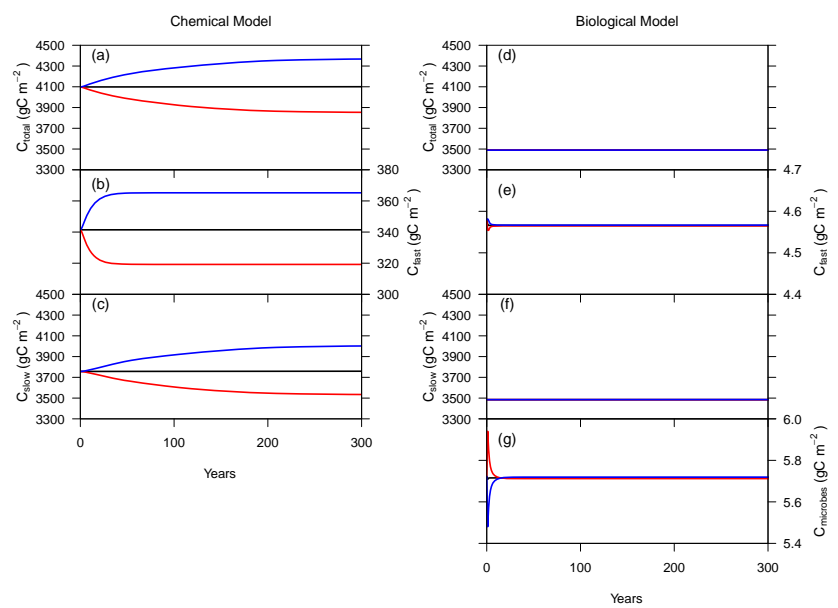

Figure 6. Soil carbon stocks of the chemical and biological models for the temperature change experiments. (a) is the total soil carbon $\left(C_{\text {total }}, \mathrm{g} \mathrm{C} \mathrm{m}^{-2}\right)$, (b) fast pool $\left(C_{\text {fast }}, \mathrm{g} \mathrm{C} \mathrm{m}^{-2}\right)$ and (c) slow pool $\left(C_{\text {slow }}, \mathrm{g} \mathrm{C} \mathrm{m}^{-2}\right)$ of the chemical model, (d) is the total soil carbon $\left(C_{\text {total }}, \mathrm{g} \mathrm{C} \mathrm{m}^{-2}\right)$, (e) fast pool $\left(C_{\text {fast }}, \mathrm{g} \mathrm{C} \mathrm{m}^{-2}\right)$, (f) slow pool $\left(C_{\text {slow }}, \mathrm{g} \mathrm{C} \mathrm{m}^{-2}\right)$ and $(\mathrm{g})$ microbial biomass $\left(C_{\text {microbes }}, \mathrm{g} \mathrm{C} \mathrm{m}^{-2}\right)$ of the biological model. Black line shows the nominal run, red line the warming and blue the cooling scenario. Only the first 300 years of the simulation are shown.

biomass increased, reduction in fast carbon due to consumption, combined with a high microbial death because of high microbial biomass, inhibited the growth of microbes reducing decomposition and respiratory losses. The initial change in microbial biomass was eventually eradicated, returning it (Fig. 6g) to its initial steady state and returning respiration back to its original value, removing any further sensitivity of temperature to respiration.

Melillo et al. (2002) also found that soil warming accelerated decomposition of soil organic matter and increased soil respiration but only for a short period of a few years. They attributed these dynamics to a reduction of the size of the labile soil carbon pool. The biological model was able to replicate the observation by Melillo et al. (2002) (Fig. 6e). The stimulation by temperature of microbial activity increased microbial biomass, increased carbon consumption and reduced labile carbon which then inhibited further microbial growth. The fact that the biological model responded similarly to many observed processes found by a number of studies (Melillo et al., 2002; Allison et al., 2010; Wetterstedt and Ågren, 2011; Frey et al., 2013) in response to temperature gives us greater confidence that the biological model was able to capture those key responses, something not possible with the chemical model. The magnitude of the responses of respiration in the biological model was somehow lower than expected, with only 5 to $6 \%$ compared to that of $40 \%$ of Allison et al. (2010), but the Arctic climate drivers for the model make comparison with the temperate location of the field experiments less straightforward. The uncertainty of some of the parameters as well as the uncertainty of the parameterization process itself might have been the reason for the low response, and further testing with assimilation of observational data is required to increase the confidence of the model outputs.

On the other hand, the chemical model showed a very different response to the observations by Melillo et al. (2002), with the labile carbon actually growing with warming. In general, the model showed a rapid response to temperature change due to a direct link of decomposition with temperature. The rate at which $\mathrm{C}$ stocks responded to climate change was higher for $C_{\text {fast }}$ than $C_{\text {slow }}$. We found that soil respiration of the chemical model increased in the first year by $\sim 6 \%$ (data not shown) but had not reached its original steady-state value at the end of the 1000-year simulation. The chemical model was not able to show the fast drop in respiration because $\mathrm{C}$ stocks continued to change and reached a steady state (Fig. 6a), much later than in the biological model. This chemical response did not allow respiration to recover to its steady-state value, thus not reproducing any of the responses found by Luo et al. (2001), Melillo et al. (2002) or Allison et al. (2010).

The acclimatization of soil respiration, the buffering of $\mathrm{C}$ stocks and the high sensitivity of SOC decomposition to the quality of the litter were the three major differences highlighted by our direct comparison between the biological and chemical model. The two models were kept as similar as possible and only differed in the way microbial activity was incorporated into decomposition processes and, critically, the activity of the fast labile pool. In the biological model, $C_{\text {fast }}$ was nothing more that a pathway of carbon between litter and microbial community. This made a pool with very fast turnover rates. In contrast, $C_{\text {fast }}$ in the chemical model is another pool like $C_{\text {slow }}$, but with the difference of a faster decomposition rate. To understand the results of our study it is important to separate the conceptual difference of the fast pool between the two models. The differences we observed between the two models were because of the difference in the concept of carbon flow from litter to soil and how microbial influence was introduced through the concept of microbial activity.

Using such an alternative model, which introduces buffering of SOC to litter quantity and temperature and a sensitivity to litter quality, can give us a different understanding of the sensitivity of Arctic C stocks to global change.

\section{Conclusions}

Microbial activity, and its related priming, is a process absent from most models of soil organic carbon decomposition (Jenkinson and Rayner, 1977; Parton et al., 1988; Li et al., 1992, 1997; Metherell et al., 1993; Coleman et al., 1997; Smith et al., 2007, 2010). While priming has largely been studied in short-term incubation studies, field research 
by Blagodatsky et al. $(1998,2010,2011)$ has recently highlighted its importance also in Arctic ecosystems (Allison et al., 2010; Schmidt et al., 2011; Hartley et al., 2012; Frey et al., 2013). The modelling challenge is to extend the shortterm understanding from incubation to long-term responses, to underpin studies on the impact of warming and linked vegetation changes on existing soil $\mathrm{C}$ stocks of the high latitudes.

The standard chemical model showed more significant long-term responses of SOC to changes in climate and litter inputs, whereas in the biological model microbial processes rapidly responded to buffer $\mathrm{C}$ stocks against these changes. Microbial processes adjusted at a finer temporal scale with rapid microbial turnover stabilizing the main $\mathrm{C}$ stocks. In contrast, the chemical model was slow to respond, but ultimately was much more responsive to forcing over the longer term.

The advantages of using a biological model are that it allows the investigation of complex interactions between microbes, litter quality, quantity and temperature. These complex interactions are likely to be more important when vertical variability of the soil profile is introduced (Schmidt et al., 2011). Further development of the model should include such variability by allowing processes to vary with depth and introduce physical variation in temperature and biophysical processes such as diffusion of oxygen and carbon dioxide, which will affect decomposition and soil respiration.

Our study suggests that the use of a chemical model is a simplification of the reality which does not match experimental warming observations. Likewise, Wutzler and Reichstein (2008) have noted that representing active decomposers in a non-linear manner, as in DecoBio, is most suitable for describing long-term SOC dynamics. The main conclusion of the study is that by excluding the impact of microbial community we miss key processes that introduce complex, often stabilizing feedbacks (Wieder et al., 2013).

\section{Code availability}

The FORTRAN 95 source codes for both DecoChem v1.0 and DecoBio v1.0 presented in this paper are freely available either through the supplementary material or directly by contacting the authors. The code was compiled using GNU Fortran 4.6.3 compiler freely available to all Unix-based operating systems.

\section{The Supplement related to this article is available online at doi:10.5194/gmd-7-1519-2014-supplement.}

Acknowledgements. This work was funded by the NERC ARCC project. We thank two anonymous reviewers for their inputs, and J. Exbrayat for helpful comments.

Edited by: D. Lunt

\section{References}

Allison, S. D., Wallenstein, M. D., and Bradford, M. A.: Soil-carbon response to warming dependent on microbial physiology, Nat. Geosci., 3, 336-340, 2010.

Blagodatsky, S. A., Blagodatskaya, E., Yuyukina, T., and Kuzyakov, Y.: Model of apparent and real priming effects: Linking microbial activity with soil organic matter decomposition, Soil Biol. Biochem., 42, 1275-1283, 2010.

Blagodatsky, S. A., Rüdiger, G., Kiese, R., Werner, C., and Butterbach-Bahl, K.: Modelling of microbial carbon and nitrogen turnover in soil with special emphasis on N-trace gases emission, Plant Soil, 346, 297-330, 2011.

Blagodatsky, S. A., Yevdokimov, I. V., Larionova, A. A., and Richter, J.: Microbial growth in soil and nitrogen turnover: Model calibration with laboratory data, Soil Biol. Biochem., 13, 1757-1764, 1998.

Chapin, F., McKendrick, J., and Johnson, D.: Seasonal changes in carbon fractions in Alaskan tundra plants of differing growth form: implications for herbivory, J. Ecol., 74, 707-731, 1986.

Coleman, K., Jenkinson, D., Crocker, G., Grace, P., Klír, J., Körchens, M., Poulton, P., and Richter, D.: Simulating trends in soil organic carbon in long-term experiments using RothC-26.3, Geoderma, 81, 29-44, 1997.

Fenner, N. and Freeman, C.: Drought-induced carbon loss in peatlands, Nat. Geosci., 4, 895-900, 2011.

Frey, S. D., Lee, J., Melillo, J. M., and Six, J.: The temperature response of soil microbial efficiency and its feedback to climate, Nature Climate Change, 3, 395-398, 2013.

Hartley, I. P., Garnett, M. H., Sommerkorn, M., Hopkins, D. W., Fletcher, B. J., Sloan, V. L., Phoenix, G. K., and Wookey, P. A.: A potential loss of carbon associated with great plant growth in the European Arctic, Nature Climate Change, 2, 875-879, 2012.

Ise, T., Dunn, A. L., Wofsy, S. C., and Moorcroft, P. R.: High sensitivity of peat decomposition to climate change through watertable feedback, Nat. Geosci., 1, 763-766, 2008.

Jenkinson, D. and Rayner, J.: The turnover of soil organic matter in some of the Rothamsted classical experiments, Soil Sci., 123, 298-305, 1977.

Jorgenson, T., Romanovsky, V., Jarden, J., Shur, Y., O’Donnel, J., Schuur, E., Kanavskiy, M., and Marchenko, S.: Resilience and vulnerability of permafrost to climate change, Can. J. Forest Res., 40, 1219-1236, 2010.

Koven, C., Ringeval, B., Friedlingstein, P. Ciais, P., Cadule, P., Khvorostyanov, D., Krinner, G., and Tamocai, C.: Permafrost carbon-climate feedbacks accelerate global warming, P. Natl. Acad. Sci., 108, 14769-14774, 2011.

Li, C., Frolking, S., and Frolking, T.: A model of nitrous oxide evolution from soil driven by rainfall events: 1 . Model structure and sensitivity, J. Geophys. Res., 97, 9759-9776, 1992.

Li, C., Frolking, S., Crocker, G., Grace, P., Klír, J., Körchens, M., and Poulton, P.: Simulating trends in soil organic carbon in longterm experiments using the DNDC model, Geoderma, 81, 45-60, 1997.

Liski, J., Palosuo, T., Peltoniemi, M., and Sievänen: Carbon and decomposition model Yasso for forest soils, Ecol. Model., 189, 168-182, 2005.

Luo, Y., Wan, S., Hui, D., and Wallace, L.: Acclimatization of soil respiration to warming in a tall grass prairie, Nature, 413, 622$625,2001$. 
Mahecha, M. D., Reichesten, M., Carvalhais, N., Lasslope, G., Lange, H., Seneviratne, S. I., Vargas, R., Ammann, C., Altaf Arrain, M., Cescatti, A., Janssens, I. A. Migliavacca, M., Montagnani, L., and Richardson, A. D.: Global convergence in the temperature sensitivity of respiration at ecosystem level, Science, 329, 838-840, 2010.

McGuire, D., Anderson, L., Christensen, T., Dallimore, S., Guo, L., Hayes, D., Heimann, M., Lorenson, T., MacDonald, R., and Roulet, N.: Sensitivity of the carbon cycle in the Arctic to climate change, Ecol. Monogr., 79, 523-555, 2009.

Melillo, J. M., Steudler, P. A., Aber, J. D., Newkirk, K., Lux, H., Bowles, F. P., Catricala, C., Magill, A., Ahrens, T., and Morrisseau, S.: Soil warming and carbon-cycle feedbacks to the climate system, Science, 298, 2173-2176, 2002.

Metherell, A., Harding, L., Cole, C., and Parton, W.: CENTURY soil organic matter model environment. Technical documentation. Agroecosystem version .0, Tech. rep., Great Plains System Research Unit, 1993.

Panikov, N. S.: Microbial growth kinetics, Springer, 1995.

Parton, W., Steward, J., and Cole, C.: Dynamics of C, N, P and S in grassland soils: a model., Biogeochemistry, 5, 109-131, 1988.

Rogers, M., Sullivan, P., and Welker, J.: Evidence of nonlinearity in the response of net ecosystem $\mathrm{CO}_{2}$ exchange to increasing levels of winter snow depth in the high Arctic of Northwest Greenland, Arct. Antarct. Alp. Res., 43, 95-106, 2011.

Sanderson, M., Hemming, D., and Betts, R.: Regional temperature and precipitation changes under high-end $\left(\geq 4{ }^{\circ} \mathrm{C}\right)$ global warming, Philos. T. Roy. Soc., 369, 85-98, 2011.

Schädel, C., Luo, Y., Evans, D. R., Fei, S., and Schaeffer, S. M.: Separating soil $\mathrm{CO}_{2}$ efflux into C-pool-specific decay rates via inverse analysis of soil incubation data, Oecologia, 171, 721732,2013

Schmidt, M., Torn, M., Abiven, S., Dittmar, T., Guggenberger, G., Janssens, I., Kleber, M., Kögel-Knabner, I., Lehmann, J., Manning, D., Nannipieri, P., Rasse, D. P., Weiner, S., and Trumbore, E.: Persistence of soil organic matter as an ecosystem property, Nature, 478, 49-56, 2011.

Sloan, V. L., Benjemin, J. F., Press, M. C., Williams, M., and Phoenix, G. K.: Leaf and root carbon stocks and turnover are coupled across multiple Arctic ecosystems, Glob. Change Biol., 19, 3668-3676, 2013.

Smith, J., Gottschalk, P., Bellarby, J., Chapman, S., Lilly, A., Towers, W., Bell, J., Coleman, K., Nayak, D., Richards, M., Hillier, J., Flynn, H., Wattenbach, M., Aitkenhead, M., Yeluripati, J., Farmer, J., Milne, R., Thomson, M., Evans, C., Whitmore, A., Falloon, P., and Smith, P.: Estimating changes in Scottish soil carbon stocks using ECOSSE. I. Model description and uncertainties, Clim. Res., 45, 179-192, 2010.
Smith, P., Smith, J., Flynn, H., Killham, K., Rangel-Castro, I., Foereid, B., Aitkenhead, M., Chapman, S., Towers, W., Bell, J., Lumsdon, D., Milne, R., Thomson, A., Simmons, I., Skiba, U., Reynolds, B., Evans, C., Frogbrook, Z., Bradley, I., Whitmore, A., and Falloon, P.: ECOSSE: Estimating carbon in organic soils - Sequestration and emissions, Final Report, Tech. rep., Scottish Executive, 2007.

Street, L. E., Subke, J. A., Sommerkom, M., Sloan, V., Ducrotoy, H., Phoenix, G. K., and Williams, M.: The role of mosses in carbon uptake and partitioning in Arctic vegetation, New Phytol., 199, 163-175, 2013.

Tarnocai, C., Canadell, J., Schuur, E., Kuhry, P., and Mazhitova, G.: Soil organic carbon pools in the northern circumpolar permafrost region, Global Biogeochem. Cy., 23, GB2023, doi:10.1029/2008GB003327, 2009.

Turetsky, M. R., Crow, S. E., Evans, R. J., Vitt, D. H., and Weider, K. R.: Trade-offs in resource allocation among moss species control decomposition in boreal peatlands, J. Ecol., 96, 1297-1305, 2008.

Wetterstedt, J. A. M. and Ågren, G. I.: Quality or decomposer efficiency - Which is most important in the temperature response of litter decomposition? A modeling study using the GLUE methodology, Biogeochemistry, 8, 477-487, 2011.

Wieder, W. R., Bonan, G. B., and Allison, S. D.: Global soil carbon projections are improved by modelling microbial processes, Nature, 3, 909-912, 2013.

Wisser, D., Marchenko, S., Talbot, J., Treat, C., and Frolking, S.: Soil temperature response to 21 st century global warming: the role of and some implications for peat carbon in thawing permafrost soils in North America, Earth Syst. Dynam., 2, 121-138, doi:10.5194/esd-2-121-2011, 2011.

Wutzler, T. and Reichstein, M.: Colimitation of decomposition by substrate and decomposers - a comparison of model formulations, Biogeosciences, 5, 749-759, doi:10.5194/bg-5-749-2008, 2008.

Xenakis, G., Ray, D., and Mencuccini, M.: Sensitivity and uncertainty analysis from a coupled 3-PG and soil organic matter decomposition model, Ecol. Model., 219, 1-16, 2008. 